$$
\text { 忩 }
$$

$+$

t

第

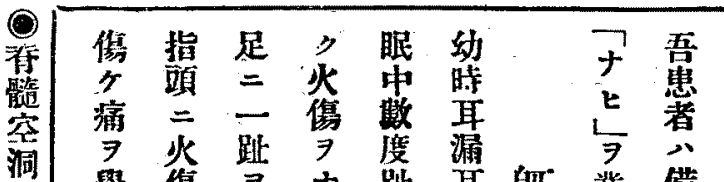

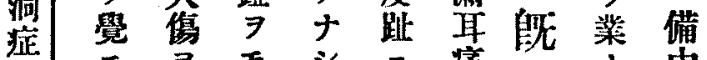

I $z \quad z=$ 痛

常 受遺 $テ$ 火

二 年一㑺 重

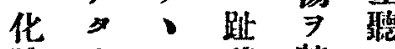

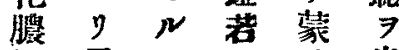

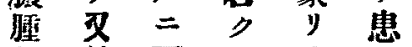

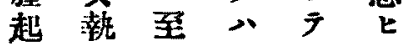

$\exists$ 業 $v$ 二

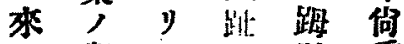

七際一 7 趾 重

少愿 昨 失 $\exists$ 聽

手釬年㫐失 $\Rightarrow$

皮为荐存

八滑二干次

肥少年五。

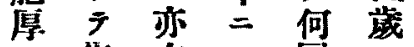

指右 打局,

夕炽第

ル $\ni$ 五雨ナ棰

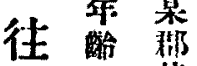

\section{年 葉}

二 某

西㷊

筬 女

ナシシ高續

天 橋

絲 情

取 金

針 -

任

及 述

婜
以.防我

上消 䌽 9

吾毒算 確

月, $7 x$

十 顥 惱 得

五 命 $\checkmark$

日發七り

追符》此

部 見此,

見 三 如

$=\bar{F}$ 本

至力病

上 本

y 月 今

昆菲

本 常 耀,

完對竻

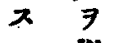

战
凊

天少

骨シテッ拇低

版告掌指市

，小》基匡

出二第面底把

$\bar{z}$ 二 $=$ 部满

夕天指皮背音入时

路卜们面筇院治

力色第肥，二後三

筑四原皮萎市

丈通指湠維

二营第把な年

短士，倠另

百 y現二惟シ物詳り水起篇

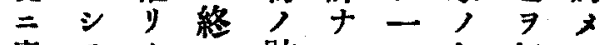

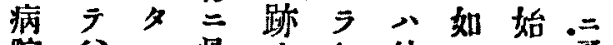

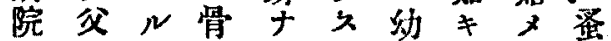

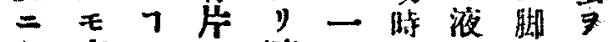
在亦ナ, 踱 》猋 出二入生量重人

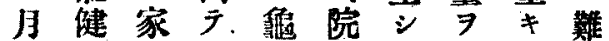
維 $八 y$ 患 $N \Rightarrow=N 夕 T$ 1

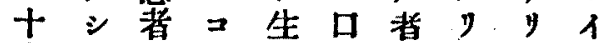
亲力展小某了

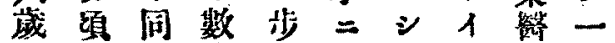
, 向一次行 $三 ;>$ 除昨 時死, 厂, 于何右出年 二已病》篇根, 卢節暮 始 三者患 太太篇脚 $习 习$

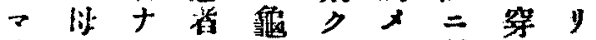
》入必裂 常强兄他, 严简 瞵

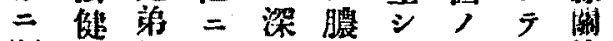

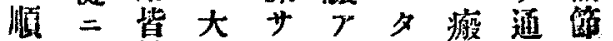
正 シ健患 $\exists$ N痕常 


\section{號一六 七 第 15}

\begin{tabular}{|c|c|c|c|c|c|c|c|c|c|c|c|c|c|c|c|c|c|}
\hline 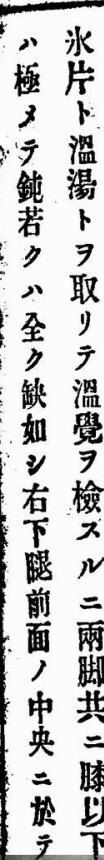 & 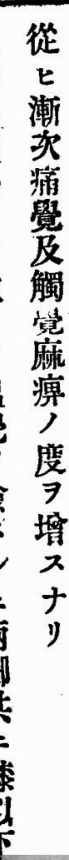 & 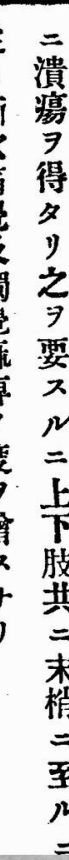 & 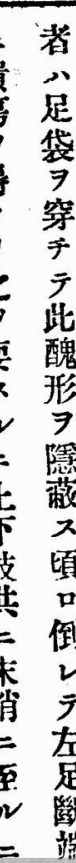 & 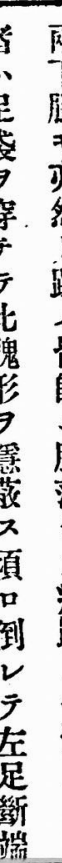 & 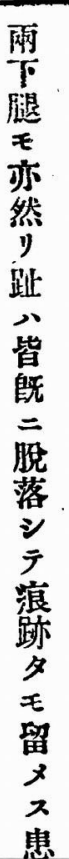 & 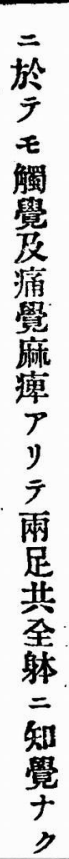 & 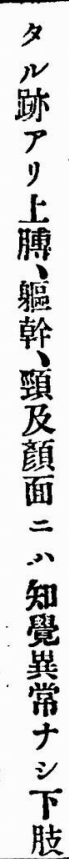 & 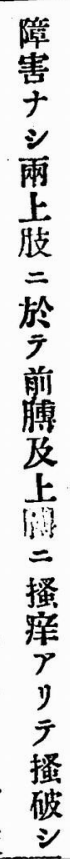 & 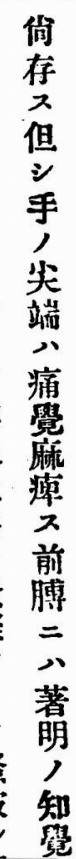 & 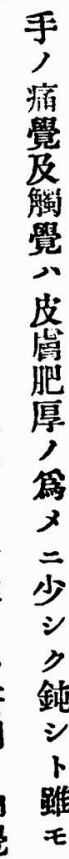 & 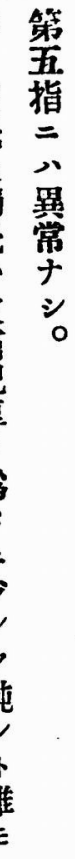 & 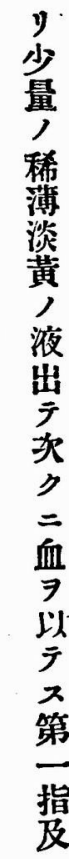 & 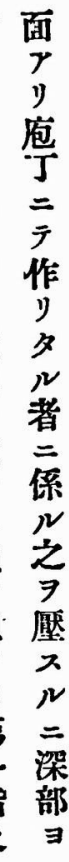 & 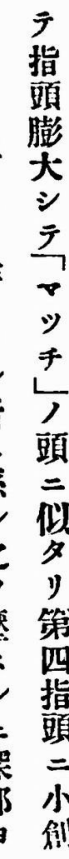 & 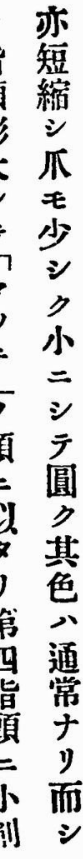 & 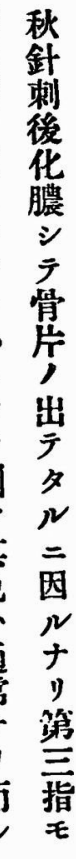 & 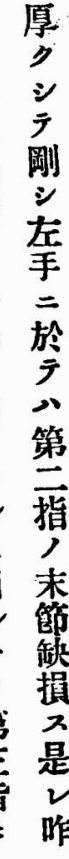 \\
\hline
\end{tabular}

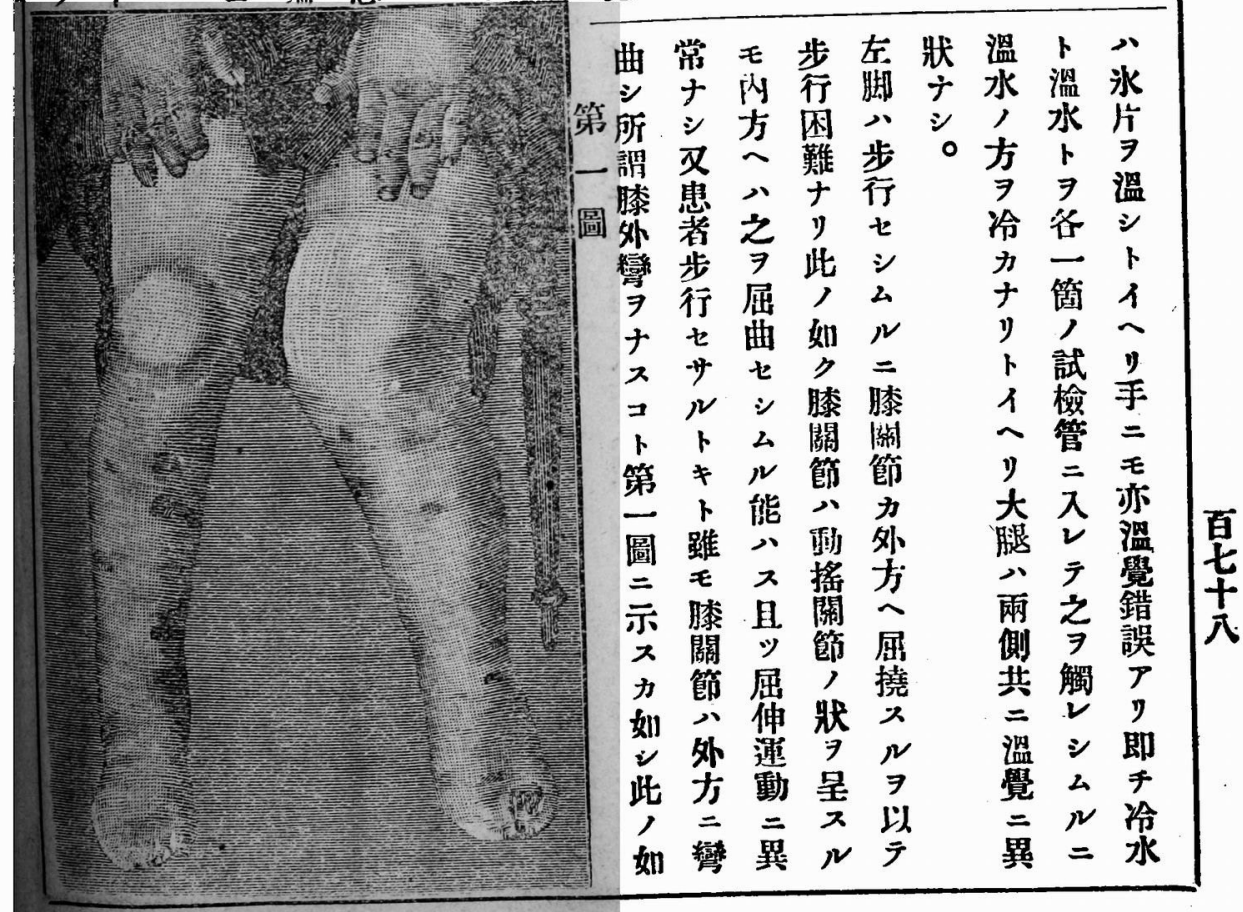


9 踑

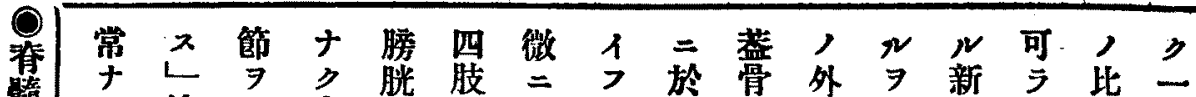
簿

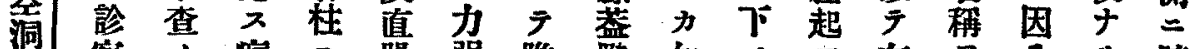

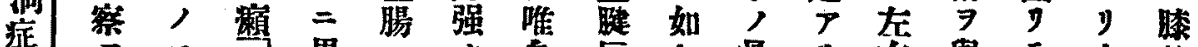
$\exists=$ 乎

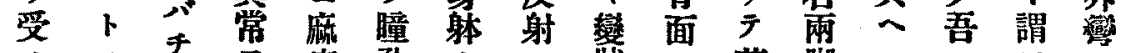

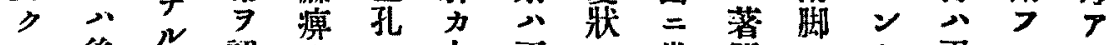
後、認大心少雨, 富明三卜螼人

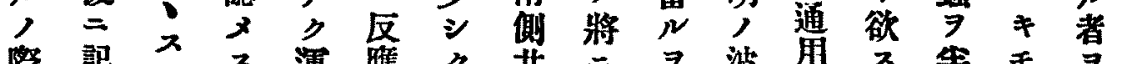

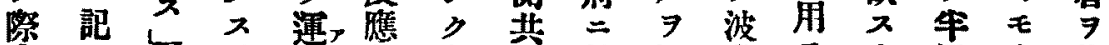

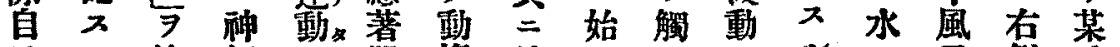
己 $\sim$ 检 經 調。明播 缺

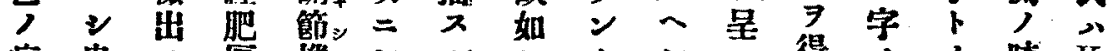

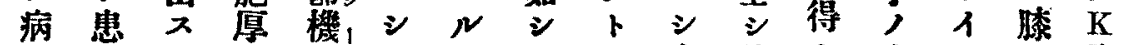

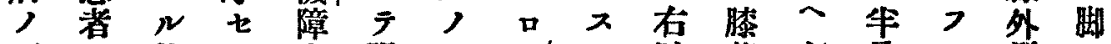

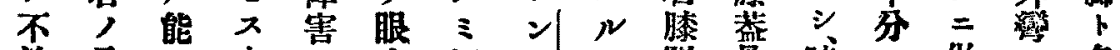

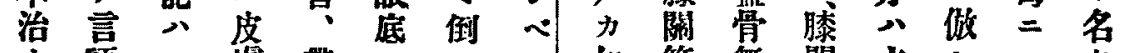

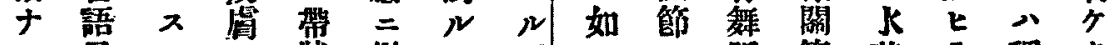
$ル$ 及

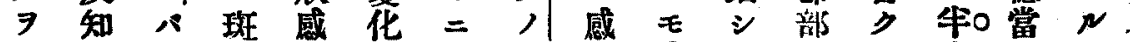
悟力 $力$ 點及至徵

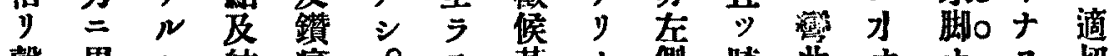

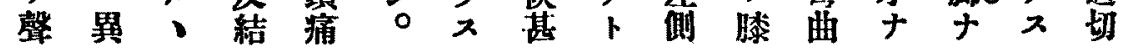

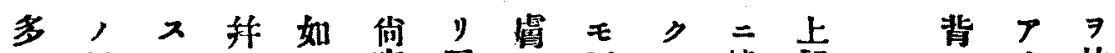

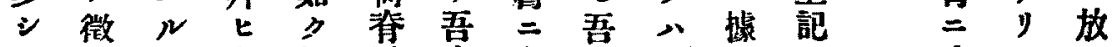

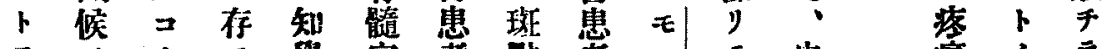
スノ卜ス學空者點著心テ皮痛人下 $N$ 現モル㥂润 $=$ 及

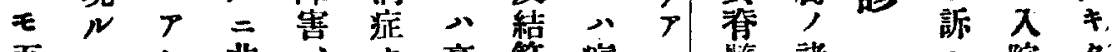
吾、v 患

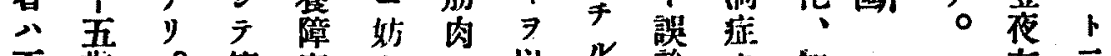

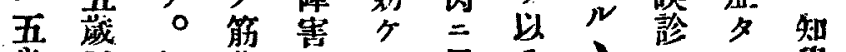

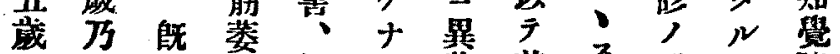
至二絤筋 $\neq$ 狀其 不恐 7 障

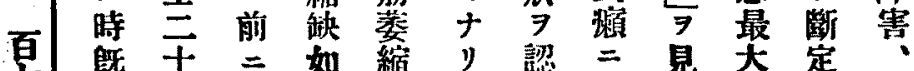
是 $=$ 既 述 如縮

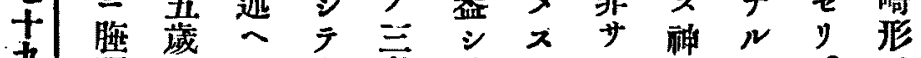

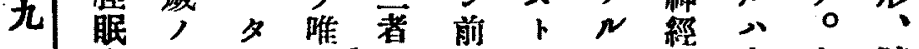
中頃 2 媻必

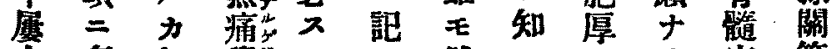

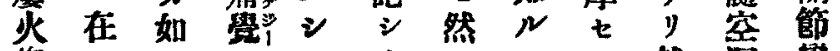

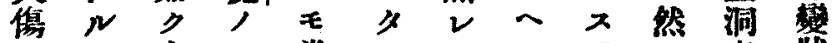

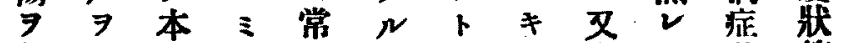
蒙最病存二カモナ皮卜若等

左 手 背 7 $=y$ 为 F 㪈 夜 , 閏 成 霄 $>$ 度 y 时 ₹ 第 管 四 二 指痛 


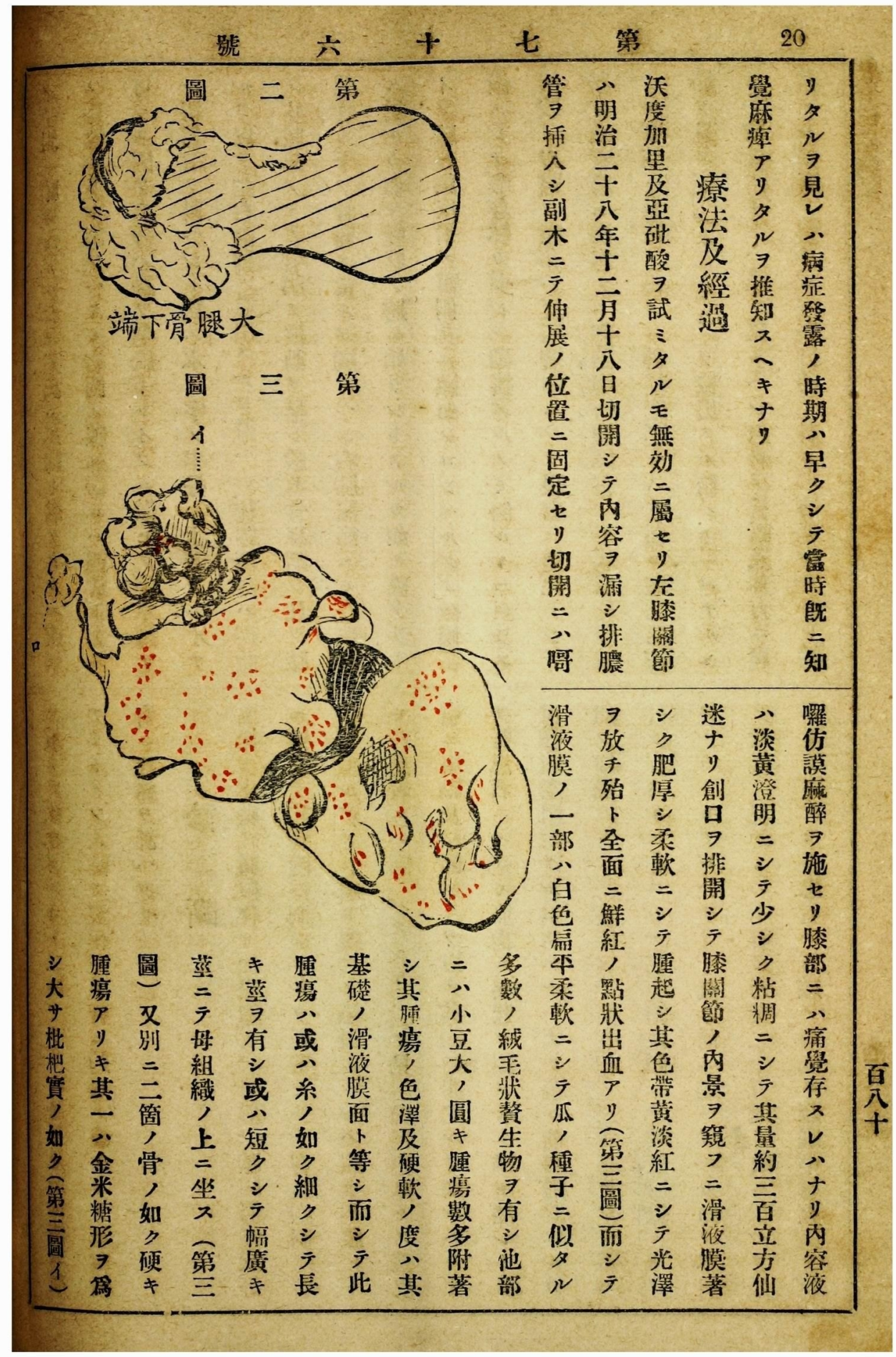




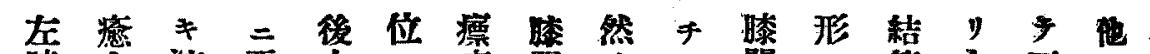

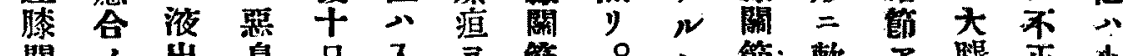
關, 出臭 日 $又 、$ 節。、節軟 $>$ 腿正办 節 傾 $\bar{Y}$ 院生手 部，向、》シ 前主街 二見緙小 小二波挠 對工帶 量縫 㑺 需 空 孔 $九 \Rightarrow$ 合方著白 $\exists$ 遂潤 膿 絲夕明二 作 $=$ 七 $7, N=$ = $y=y$ 外除 $\vec{y}$ ～

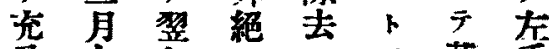

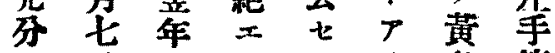
二日—ス 漏彁月手二小, 四 膿 噬 中 術一 等句時期 >容笑 道謨 二 = 瘾翌物端 $\Rightarrow$ 维及出自 7 堂 開醉フ三七發透面 多 行手 タ ス 熱 視

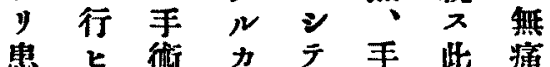
賭亏部如創街部分

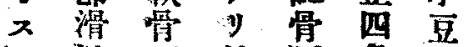

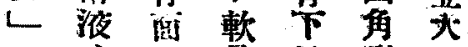

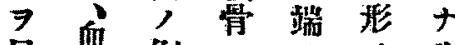
見血液制三”,

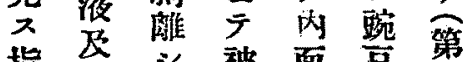
指范被面吾第 頭芺名公省

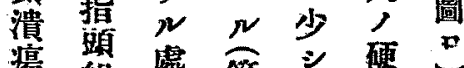
瘍䔃第 シ 便

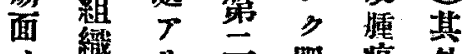

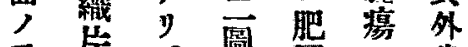
分泌。圆愿方游

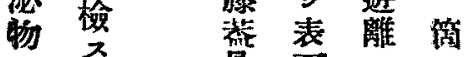

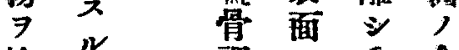
检 $N$ 裡 = 查二面數取 来 入 $\bar{z}=$ 多 $\nu$ 裙

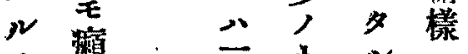
更

七要四九第東參 入手入息登

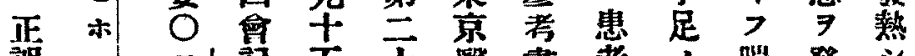

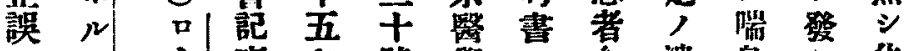

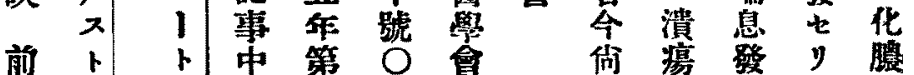

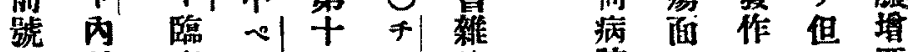

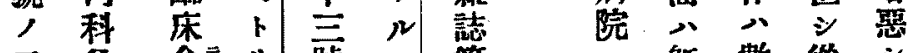

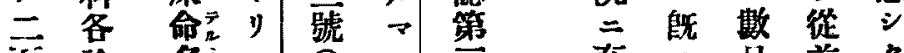
首論 名: = 毛等法落, 干 行 O'報 入 外 0

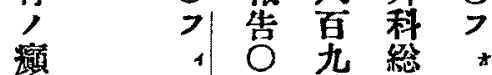

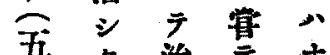
轱夕治方ナ 委 $v$ 喘 y

分毛? 息苯

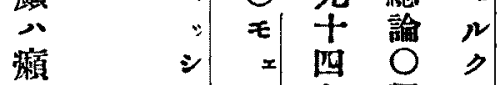

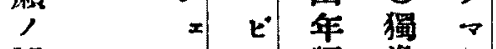
誤为方㯰逸 y外 天逸婜 臨

完和人皮事床

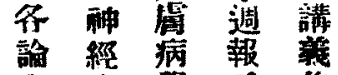
0 病 學学 厂學阋 公

旦灰

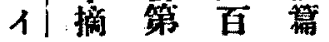

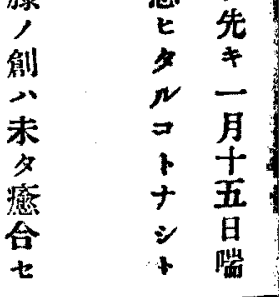

